\title{
TRACE ELEMENT ANALYSIS OF SULFUR IN A JAPANESE SWORD
}

\author{
N. Mori ${ }^{1}$, R. Kamiyama ${ }^{1}$ T. Tanaka ${ }^{2}$, T. Kimura ${ }^{1}$, Peter McSwiggen ${ }^{3}$, Hroshi Onodera ${ }^{1}$, and Charles Nielsen ${ }^{4}$ \\ 1. JEOL Ltd., 1-2 Musashino, 3 Akishima, Tokyo 196-8558 JAPAN \\ 2.National Institite for Materials Science, 1-2-1 Sengen, Tsukuba, Ibaraki 305-0047, Japan \\ 3. McSwiggen \& Associates, 2855 Anthony Lane, St. Anthony, MN 55418; \\ 4. JEOL USA, Inc., 11 Dearborn Road Peabody MA 01960
}

The Japanese sword or Nihonto is a piece of art, a wonder of metallurgical craftsmanship and - even today - a fascinating object for materials research.

A traditional Japanese sword is made from tama-hagane (literally: jewel steel). Tama-hagane is steel with a carbon content around $1 \%$ and has the chemical composition best suited for edged steels. Its composition makes it exceedingly malleable. The amount of other chemical impurities present is extremely low. Tama-hagane is obtained by a traditional method called tatara. Tatara iron manufacturing has been developed by the master sword makers for more than 1000 years.

We investigated a sword that was preserved in an old Japanese village headman house. One of the characteristics of a Japanese sword is that is consists of two different steels: a harder outer jacket of steel wrapped around a softer core of steel. A specimen including both steels was produced as crosssection perpendicular to the length of the sword. Stage mappings was performed over a large crosssectional area of $6 \mathrm{~mm} \times 30 \mathrm{~mm}$ with EPMA (JEOL JXA-8230). The outer skin of the blade showed few impurities other than carbon. A striped pattern of $\mathrm{Si}$ and $\mathrm{Al}$ due to oxide inclusions such as $\mathrm{SiO}_{2}$ and $\mathrm{Al}_{2} \mathrm{O}_{3}$ particles was clearly observed. In fact, tama-hagane manufacturing with the tatara process from iron sand contains, though small, certain amounts of $\mathrm{SiO}_{2}$ and $\mathrm{Al}_{2} \mathrm{O}_{3}$ particles. Furthermore, the manufacturing process of the Japanese sword consists of many times of folding, hammering and re-welding of the billet of steel, a process which produces a striped distribution of $\mathrm{SiO}_{2}$ and $\mathrm{Al}_{2} \mathrm{O}_{3}$ particles. The observation of the outer skin of the blade agreed very well with those made by traditional sword makers. The inner core of the sword, however, was found to contain lager amounts of $\mathrm{Mn}$ and $\mathrm{S}$ than those in tama-hagane. Quantitative analysis of S with a spot size of $50 \mu \mathrm{m}$ indicated that the inner core of the sword contained $230 \mathrm{ppm}$ whereas the outer skin of the blade contained $50 \mathrm{ppm}$. To obtain these trace amount of $\mathrm{S}$, the $\mathrm{S}-\mathrm{K} \alpha$ spectrum was measured to confirm that no discernible overlap due to other elements was present in the background. The two standard samples of ICP-MS: JSS003-1 S: 4 ppm and SS001-3 S: 2.2 ppm, were analyzed with a spot size $30 \mu \mathrm{m}$. Only $2 \mathrm{ppm}$ difference in these two standard samples could be detected with this EPMA so that the measured value of the outer skin of the blade was considered to be highly reliable. $\mathrm{S}$ inner core was found in high magnification mapping as $\mathrm{MnS}$ particles with size of few tenths of micrometres. MnS inclusions have never been observed in tama-hagane. They are rather a fingerprint of modern iron making, which started at the end of the Edo period in the middle of nineteenth century. This sword was found to be produced relatively recently about100 years old. This was classified as a contemporary work and brief method. 


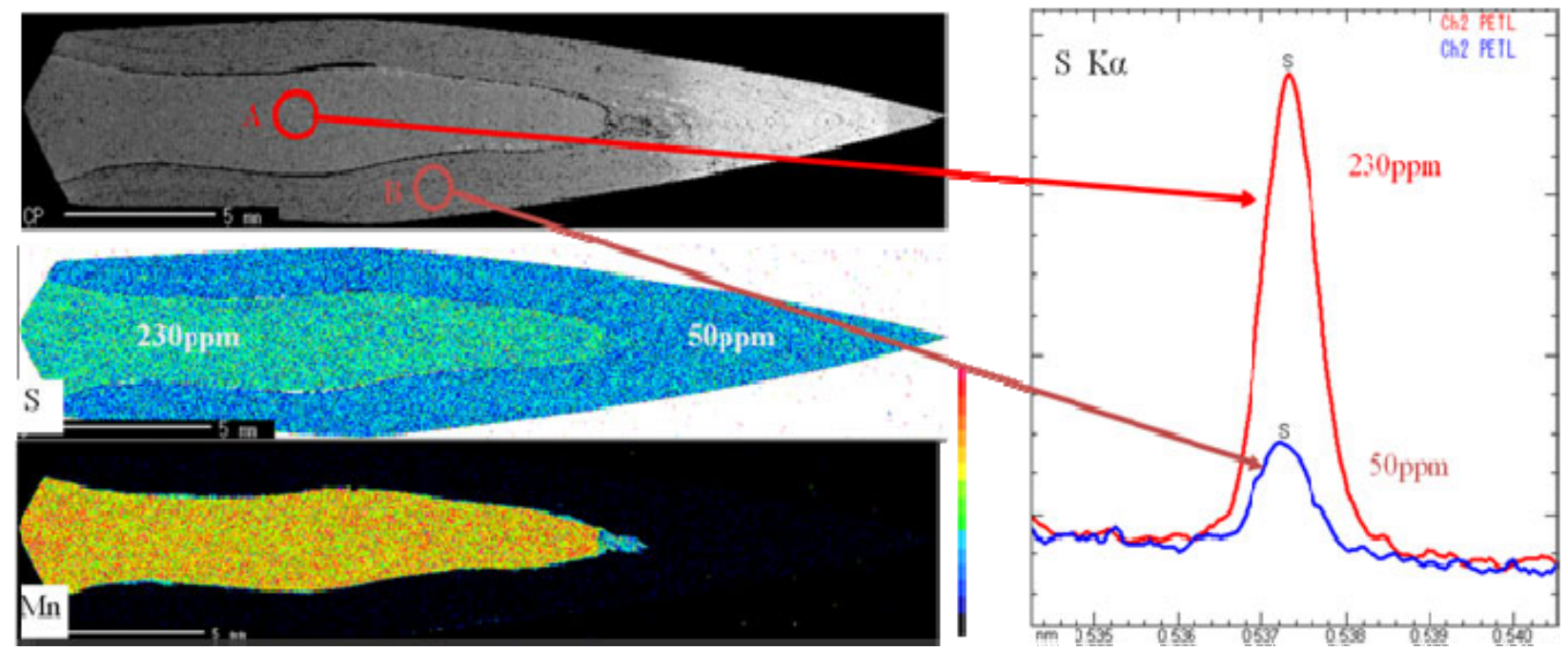

Fig. 1 The X-ray mapping and spectra of Japanese sword at an accelerating of $20 \mathrm{kV}$. This stage mapping was performed over a large cross-sectional area of $6 \mathrm{~mm}$ x $30 \mathrm{~mm}$. It is shown that this Japanese sword consists of two steel as for this data.

\begin{tabular}{|c|c|c|c|c|}
\hline Element & $\mathbf{A}($ mass $\%)$ & $\mathbf{B}($ mass $\%)$ & Detection limit $($ massppm $)$ \\
\hline $\mathrm{P}$ & 0.0159 & 0.0171 & 21 & \\
\hline $\mathrm{Ca}$ & - & 0.1034 & 96 & \\
\hline $\mathrm{Mn}$ & 0.3516 & - & 60 & \\
$\mathrm{Si}$ & 0.1365 & 0.1325 & 18 & \\
\hline $\mathrm{Al}$ & 0.0054 & 0.1090 & 18 & \\
\hline $\mathrm{Mg}$ & - & 0.0166 & 15 & \\
\hline $\mathrm{S}$ & 0.0232 & 0.0053 & 21 & \\
\hline $\mathrm{Cu}$ & 0.0155 & 0.0597 & 60 & \\
\hline $\mathrm{Cr}$ & 0.0245 & - & 45 & \\
\hline $\mathrm{C}$ & 0.3095 & 0.6054 & 21 & \\
\hline $\mathrm{Fe}$ & 99.1179 & 98.9510 & & Difference \\
\hline Total & 100.0000 & 100.0000 & & \\
\hline
\end{tabular}

Table.1. The result of the quantitative analysis of a Japanese sword at an accelerating of $20 \mathrm{kV}$.

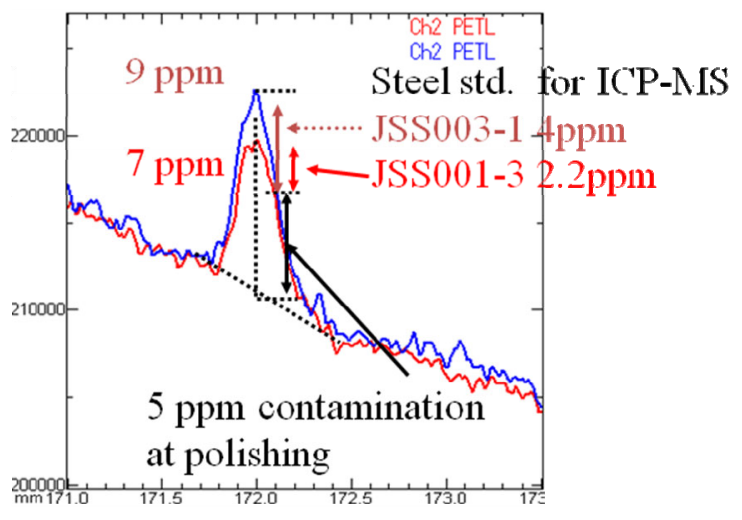

Fig.2. The result of several ppm Sulfur standard samples of ICP-MS. Only 2 ppm difference in these two standard samples could be detected with this EPMA 